\title{
Variação temporal da qualidade da água no desempenho de filtros utilizados na irrigação por gotejamento
}

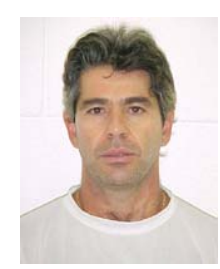

\author{
Túlio A. P. Ribeiro' ${ }^{1}$ Rogério P. S. Airoldi ${ }^{1}$, José E. S. Paterniani ${ }^{1} \&$ Marcelo J. M. da Silva² \\ 1 FEAGRI/UNICAMP. CP 6011, CEP 13083-970, Campinas, SP. Fone: (19) 37881029, Fax: (019) 3788-1010. E-mail: \\ tulior@agr.unicamp.br; rairoldi@agr.unicamp.br; pater@agr.unicamp.br. Fone: (19) 3788-1019. \\ 2 FEC/UNICAMP. E-mail: moreiradasilva@engineer.com. Fone: (19)378-82305
}

Protocolo $118-8 / 7 / 2003$ - Aprovado em 20/7/2005

\begin{abstract}
Resumo: Uma investigação experimental para se comparar o desempenho dos meios filtrantes disco (130 microns) e manta sintética não-tecida na filtração da água utilizada em um sistema de irrigação por gotejamento com tratamento químico, foi o que se objetivou através deste trabalho analisando-se, também, a variação temporal durante um ano, dos principais parâmetros da água que causam problemas de entupimento nos emissores. Utilizou-se a técnica da fertirrigação com um fertilizante organico-mineral e o tratamento químico foi feito através da cloração. A comparação dos dois meios filtrantes foi realizada através da análise da água afluente e efluente dos filtros. A água de irrigação mostrou que somente os parâmetros químicos $\mathrm{pH}$ e o ferro apresentaram médio risco de entupimento. Os demais parâmetros resultaram em valores que não apresentaram risco de entupimento dos gotejadores. A injeção da solução com fertilizante alterou a qualidade da água em relação à concentração de sólidos suspensos e turbidez. Não houve diferença no desempenho do filtro de manta e de disco com relação aos parâmetros físicos e biológicos de seus efluentes. A concentração de cloro livre foi maior no efluente do filtro de disco.
\end{abstract}

Palavras-chave: irrigação localizada, cloração, entupimentos, filtragem, manta sintética nãotecida

\section{Temporal variation of water quality and the performance of the filters utilized in drip irrigation}

\begin{abstract}
An experimental investigation was accomplished in order to compare the performance of disc filters (130 microns) and non-woven synthetic fabric in the filtration of water, used in trickle irrigation systems, with chemical treatment. The temporal variation of the principal parameters of the irrigation water that cause obstruction problems in the emitters were also analyzed during the year: the fertirrigation technique was utilized with organic mineral fertilizer, and the chemical treatment was done with chlorine. The comparison between the two filter elements was done through the analysis of affluent and effluent. The results showed that only the chemical parameters: $\mathrm{pH}$ and total iron presented medium risk to obstruction. All the others parameters, resulted in values that did not present obstruction risk to the emitters. The fertilizer solution injection changed the water quality, due to the concentration of suspended solids and turbity. There was no difference in the performance disc filters $(130$ microns) and non-woven synthetic fabric, related to the physical and biological parameters of their effluent. The free chlorine concentration was higher in the filter disc effluent.
\end{abstract}

Key words: trickle irrigation, chlorine, clogging, filtration, non-woven synthetic fabric

\section{INTRODUÇÃO}

O uso da irrigação localizada vem crescendo cada vez mais devido ao avanço tecnológico na agricultura irrigada que procura, sempre, métodos de irrigação que apresentem grande eficiência aliada à redução nos custos de produção e consumo de água e energia. Isto tem causado enorme crescimento no desenvolvimento de materiais e equipamentos que possam melhorar o desempenho nos sistemas de irrigação localizada. Um dos fatores que elevam os custos de operação e manutenção do sistema e, em certos casos, inviabilizam a utilização desse método, é a obstrução de emissores.

Normalmente, as obstruções são causadas pela combinação de três fatores (físicos, químicos e biológicos) presentes na 
água de irrigação como, por exemplo, a presença de argila e produtos de corrosão envoltos em massa biológica e cimentados com precipitados de $\mathrm{CaCO}_{3}$; no entanto, tem-se observado que os maiores problemas de obstrução são causados pela presença de materiais em suspensão, como silte, algas etc. (Adin \& Alon, 1986). Especificamente quanto ao crescimento de algas e bactérias nos mananciais utilizados para captação e nas tubulações dos sistemas de irrigação, observase um agravamento em virtude da prática da fertirrigação, técnica cada vez mais freqüente em sistemas de irrigação localizada.

English (1985) recomenda, para um tratamento preventivo de bactérias formadoras de limo, efetuar-se uma cloração em base contínua, a uma taxa de 1 a $2 \mathrm{mg} \mathrm{L}^{-1}$, ou semanalmente, a uma concentração de 10 a $20 \mathrm{mg} \mathrm{L}^{-1}$, por 30 a 60 minutos, sendo que esta última dosagem é também sugerida pelo autor para o tratamento de algas.

Processos físicos de filtragem e tratamentos químicos são muitas vezes utilizados nesses sistemas para minimizar a obstrução de emissores (Nakayama et al., 1977; Gilbert et al., 1981).

A remoção de algas por filtros de superfície não é considerada eficiente, porém poucos testes têm caracterizado a capacidade de remoção desses meios filtrantes e recentes experimentos têm demonstrado a possibilidade do uso de mantas não-tecidas como elemento filtrante na remoção de sólidos suspensos em filtros para irrigação localizada (Paterniani \& Silva, 1996).

O presente trabalho teve por objetivo realizar uma investigação experimental a fim de se comparar o desempenho de dois elementos filtrantes diferentes, na remoção de impurezas da água de irrigação localizada, quando são utilizadas as técnicas da fertirrigação e cloração como tratamento químico para o controle de algas e bactérias. Os elementos filtrantes a serem ensaiados, foram: disco (130 microns), comercialmente difundido entre os agricultores, e manta sintética não-tecida, a qual pode tornar-se uma tecnologia alternativa, mais acessível ao agricultor e tecnicamente viável.

Especificamente, foram analisados os parâmetros físico, químicos e biológicos da água afluente e efluente dos filtros que podem causar obstrução nos gotejadores, que são: pH, turbidez, sólidos suspensos totais, sólidos dissolvidos, ferro, sulfetos, algas e bactérias, durante o período de um ano.

\section{MATERIAL E MÉTODOS}

O experimento foi conduzido no município de Campinas, Estado de São Paulo. Os critérios para avaliação das impurezas presentes na água de irrigação, foram baseados nos estudos realizados por Nakayama \& Bucks (1986). A água usada no experimento era proveniente de um reservatório de $250 \mathrm{~m}^{3}$, constituído de um pequeno açude, que é abastecido pelo bombeamento de água de uma pequena represa, onde ocorre a contribuição hídrica de outras nascentes que estão ao seu redor.

$\mathrm{Na}$ área experimental foi montado um sistema de irrigação composto de uma motobomba centrífuga, um controlador automático de irrigação, duas válvulas elétricas com solenóide, gotejadores, dois transdutores diferenciais de pressão, dois reguladores de pressão, três hidrômetros digitais tipo turbina, na faixa de 10 a $100 \mathrm{~L} \mathrm{~min}^{-1}$, dois manômetros de Bourdon, sistema de injeção de fertilizantes e cloro, constituído de duas bombas dosadoras de pistão, sistema de filtragem composto de dois filtros, sendo um filtro de disco de 130 microns, diâmetro de 25,4 mm da marca Amiad e um de manta sintética, cujo esquema está na Figura 1.

Para a realização da fertirrigação utilizou-se um fertilizante organo-mineral. O produto apresenta-se na forma líquida e sua composição, segundo o fabricante, é de $25 \%$ matéria orgânica, $3 \%$ de nitrogênio total e $9 \%$ de potássio na forma de $\mathrm{K}_{2} \mathrm{O}$. A solução de fertilizantes a ser injetada era feita uma vez por mês em um recipiente plástico totalmente fechado.

A escolha do tipo de manta sintética não-tecida foi feita segundo estudos já realizados por Scatolini (2001). Os corpos dos dois filtros eram idênticos e feito de plástico, somente o elemento filtrante era diferente. Com tal procedimento pôdese garantir semelhança funcional entre os filtros. As características da manta sintética não tecida utilizada como meio filtrante possui permeabilidade normal de $0,5 \mathrm{~cm} \mathrm{~s}^{-1}$, permissividade de $1,6 \mathrm{~s}^{-1}$, abertura dos poros de $0,150 \mathrm{~mm}$, gramatura de $380 \mathrm{~g} \mathrm{~m}^{-2} \mathrm{e}$ espessura $3,8 \mathrm{~mm}$.

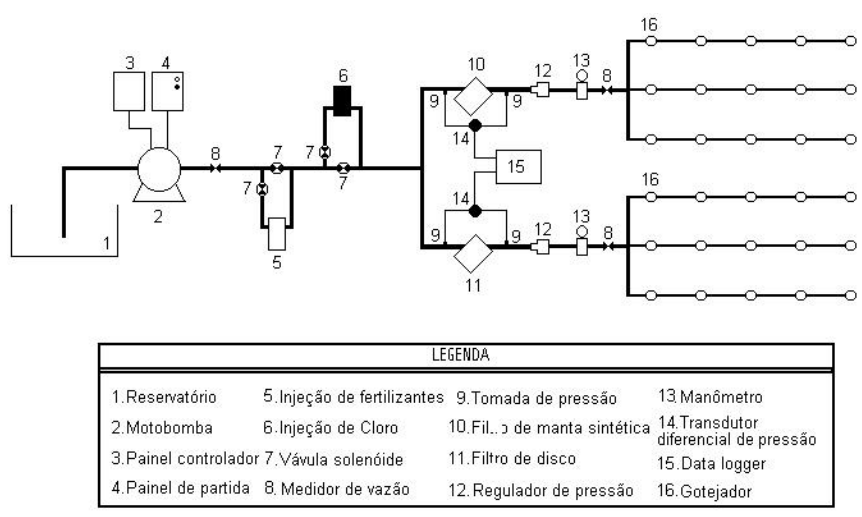

Figura 1. Esquema dos sistema de irrigação

Os ensaios dos filtros foram realizados com água superficial captada de um reservatório, no qual foi instalado um conjunto de bombeamento que alimentou os dois filtros colocados em paralelo e, portanto, sob as mesmas condições de perda de carga. A vazão média através de cada filtro foi de $600 \mathrm{~L} \mathrm{~h}^{-1} \mathrm{e}$, para garantir pressão igual nos filtros, instalaram-se reguladores de pressão de 69,94 $\mathrm{kPa}$.

Os ciclos de irrigação foram feitos através de um controlador de irrigação, programado para acionar o sistema duas vezes ao dia, pela manhã e no final da tarde. O tempo de irrigação foi de duas horas, sendo a injeção de fertilizantes na linha principal do sistema, realizada em uma hora e meia, e a aplicação de água com cloro no tempo restante. A fonte de cloro utilizada foi o hipoclorito de sódio (12\%). Adotou-se o valor da concentração de cloro necessária na linha de gotejadores de $2 \mathrm{mg} \mathrm{L}^{-1}$. Uma concentração de 1 a $2 \mathrm{mg} \mathrm{L}^{-1} \mathrm{de}$ cloro livre nas linhas de gotejadores foi utilizada para o controle preventivo de entupimento com relação ao controle de algas e limos (English, 1985).

As amostragens da água do reservatório foram realizadas nas quatro estações do ano, entre 2001 e 2002. Nas amostragens 
de campo determinaram-se fatores relacionados com a qualidade de água para irrigação localizada e que podem causar obstrução nos gotejadores, como: pH, sólidos em suspensão ( $\mathrm{Ss}$ ), turbidez, sólidos dissolvidos, ferro total (Fe), sulfetos de hidrogênio $\left(\mathrm{H}_{2} \mathrm{~S}\right)$, concentração de algas e bactérias. O ponto de coleta era localizado na linha principal de irrigação, depois do sistema de bombeamento e antes do sistema injetor de fertilizantes. A classificação da água para o sistema de irrigação localizada em relação a problemas de entupimento devido a fatores físicos, químicos e biológicos, seguiu recomendações de Nakayama \& Bucks (1986).

A determinação da população bacteriana foi realizada pelo método de contagem em placa de Petri, utilizando-se ágar (triptona, glucose e extrato de levedura) como meio de cultura e tempo de contagem de 48 horas (APHA, 1992).

A contagem de algas se deu pelo método de SedgwickRafter, de acordo com o Standard methods for the examination of water and wastewater" (APHA, 1985)

\section{RESULTADOS E DISCUSSÃO}

\section{Variação temporal da qualidade da água}

De maneira geral, pode-se afirmar que a qualidade da água utilizada para irrigação do sistema de gotejamento variou durante as diferentes épocas do ano, sendo que o risco potencial de entupimento dos gotejadores só foi médio ou alto com relação aos parâmetros químicos (ferro, sulfetos e pH), cujos resultados estão apresentados na Tabela 1 .
Os valores de $\mathrm{pH}$ encontrados no decorrer desta pesquisa são semelhantes aos obtidos por Testezlaf et al. (1994), que verificaram a potencialidade do uso de água de reservatórios e rios para uso em sistemas de irrigação por gotejamento, em propriedades agrícolas produtoras de hortaliças na região de Campinas. Constatou-se que em 27 fontes hídricas analisadas, $88,9 \%$ apresentaram $\mathrm{pH}$ alcalino e risco moderado de entupimento segundo a mesma classificação adotada nesta pesquisa.

Problemas com interações bactéria-ferro têm ocorrido com concentrações de ferro tão baixas quanto $0,1 \mathrm{mg} \mathrm{L}^{-1}$. Teores deste íon superiores a $0,2 \mathrm{mg} \mathrm{L}^{-1}$ são considerados como de risco significativo de entupimento (English, 1985). O ferro precipitado forma uma incrustação vermelha, a qual pode aderir ao PVC da tubulação e entupir os emissores. Algumas bactérias filamentosas, como Gallionella, Crenothrix e Leptothrix, oxidam o $\mathrm{Fe}^{+2}$, transformando-o em $\mathrm{Fe}^{+3}$ que pode precipitar-se e provocar entupimento (Ford \& Tucker, 1986; Pizarro, 1996). Estas bactérias têm importância econômica e sanitária, causando a formação de crostas de ferrugem no interior de tubos ou de residências, precipitando hidróxido férrico em águas ricas nesse elemento. Elas chegam a formar extensos depósitos geológicos de ferro e, nas canalizações, constituem freqüentes causas de obstruções, além de dar uma coloração pardoavermelhada à água. Para o controle dessas bactérias, tem-se utilizado algum tipo de desinfetante, como o cloro e o sulfato de cobre; este último tem sido empregado com sucesso em dosagens de 0,3 a $0,5 \mathrm{mg} \mathrm{L}^{-1}$ para o controle de ferrobactérias, como a Crenothrix (Branco, 1986).

Tabela 1. Fatores físicos, químicos e biológicos na água de irrigação durante as quatro etapas do ano

\begin{tabular}{|c|c|c|c|c|c|c|c|c|c|}
\hline & & \multicolumn{2}{|c|}{ Físicos } & \multicolumn{4}{|c|}{ Químicos } & \multicolumn{2}{|c|}{ Biológicos } \\
\hline & & $\begin{array}{l}\text { Sólidos } \\
\text { Suspensos } \\
\left(\mathrm{mg} \mathrm{L}^{-1}\right)\end{array}$ & $\begin{array}{c}\text { Turbidez } \\
\text { NTU }\end{array}$ & $\mathrm{pH}$ & $\begin{array}{c}\text { Ferro } \\
\left(\mathrm{mg} \mathrm{L}^{-1}\right)\end{array}$ & $\begin{array}{l}\text { Sulfetos } \\
\left(\mathrm{mg} \mathrm{L}^{-1}\right)\end{array}$ & $\begin{array}{c}\text { Sólidos } \\
\text { Dissolvidos } \\
\left(\mathrm{mg} \mathrm{L}^{-1}\right)\end{array}$ & $\begin{array}{c}\text { Algas } \\
\left(n^{0} \mathrm{~cm}^{-3}\right)\end{array}$ & $\begin{array}{l}\text { Bactérias } \\
\left(\mathrm{n}^{0} \mathrm{~cm}^{-3}\right)\end{array}$ \\
\hline \multirow{5}{*}{ 苞 } & Variação & $1,0-5,0$ & $1,82-3,88$ & $7,1-7,5$ & $0,4-1,0$ & $1,0-2,0$ & $28,8-48,64$ & $165-1295$ & $270-6500$ \\
\hline & Média & 2,67 & 2,83 & 7,33 & 0,52 & 1,10 & 37,70 & 497 & 2438 \\
\hline & Desv. Pad. ${ }^{1}$ & 1,51 & 0,68 & 0,23 & 0,18 & 0,32 & 6,33 & 345 & 2812 \\
\hline & C.V. ${ }^{2}(\%)$ & 56,46 & 24,18 & 3,09 & 33,68 & 28,75 & 16,79 & 69,46 & 115,36 \\
\hline & Risco de entup ${ }^{3}$ & $\mathrm{~B}$ & $\mathrm{~S} / \mathrm{C}$ & M & $\mathrm{M}$ & M & $\mathrm{B}$ & $\mathrm{S} / \mathrm{C}$ & B \\
\hline \multirow{5}{*}{ 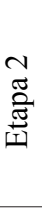 } & Variação & $8,5-13,5$ & $5,19-11,9$ & $6,4-8,1$ & $0,5-1,7$ & $1,0-9,0$ & $26,8-38,40$ & 1377 & 1202 \\
\hline & Média & 10,96 & 8,27 & 7,39 & 1,10 & 2,42 & 32,21 & 287 & 2065 \\
\hline & Desv. Pad. ${ }^{1}$ & 1,37 & 1,91 & 0,46 & 0,38 & 2,27 & 3,68 & 20,88 & 171,81 \\
\hline & C.V. ${ }^{2}(\%)$ & 12,53 & 23,13 & 6,23 & 34,89 & 94,13 & 11,42 & $\mathrm{~S} / \mathrm{C}$ & B \\
\hline & Risco de entup ${ }^{3}$ & $\mathrm{~B}$ & $\mathrm{~S} / \mathrm{C}$ & M & M & A & B & 1377 & 1202 \\
\hline \multirow{5}{*}{ 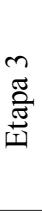 } & Variação & $12,5-19$ & $7,12-16,9$ & $6,8-7,8$ & $0,2-1,0$ & $1,0-5,0$ & $26,88-35,84$ & $120-705$ & $10-760$ \\
\hline & Média & 17,61 & 11,30 & 7,13 & 0,74 & 2,83 & 31,72 & 459 & 223 \\
\hline & Desv. Pad. ${ }^{1}$ & 4,17 & 2,93 & 0,42 & 0,26 & 1,17 & 2,64 & 179 & 236 \\
\hline & C.V. ${ }^{2}(\%)$ & 23,66 & 25,95 & 5,86 & 34,97 & 41,39 & 8,33 & 38,97 & 105,74 \\
\hline & Risco de entup ${ }^{3}$ & B & $\mathrm{S} / \mathrm{C}$ & M & M & A & B & $\mathrm{S} / \mathrm{C}$ & B \\
\hline \multirow{5}{*}{ 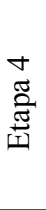 } & Variação & $16,0-23,5$ & $7,45-14,5$ & $6,6-7,3$ & $0,0-1,0$ & $2,0-16$ & $20,48-57,60$ & $205-950$ & $200-5400$ \\
\hline & Média & 19,7 & 10,14 & 6,88 & 0,48 & 3,50 & 38,02 & 512 & 1702 \\
\hline & Desv. Pad. ${ }^{1}$ & 2,51 & 2,23 & 0,19 & 0,32 & 4,40 & 10,65 & 216 & 1798 \\
\hline & C.V. ${ }^{2}(\%)$ & 12,78 & 21,97 & 2,89 & 66,46 & 125,81 & 28,00 & 42,12 & 105,62 \\
\hline & Risco de entup ${ }^{3}$ & B & $\mathrm{S} / \mathrm{C}$ & B & $\mathrm{M}$ & A & B & $\mathrm{S} / \mathrm{C}$ & B \\
\hline
\end{tabular}

${ }^{1}$ Desvio padrão da média; ${ }^{2}$ Coeficiente de variação; ${ }^{3}$ B: baixo risco; M: médio risco; A: alto risco;

S/C: sem classificação 
As concentrações de algas e bactérias apresentaram coeficientes de variação elevados durante cada estação do ano e também variações significativas entre as estações. A mudança dinâmica da população de algas pode representar um risco ao sistema, se não houver um tratamento eficiente da água de irrigação, e indica grande sensibilidade desses organismos com relação à variação da qualidade da água. As variações sazonais de algas em regiões tropicais, onde a luz e a temperatura da água não variam muito durante o ano, são devidos ao efeito das chuvas ou seca e, fundamentalmente, da ação dos ventos. A coincidência entre uma ligeira diminuição da temperatura e aumento da intensidade e da duração de ventos, pode causar a circulação da água em profundidades maiores e, conseqüentemente, uma variação brusca na concentração de algas. Para estudos quantitativos de algas, há necessidade de se levar em conta que a distribuição espacial das populações de algas não é uniforme e que variações, tanto sazonais quanto espaciais, podem ser apreciáveis. Não há um método universal para a coleta de amostra que garanta a presença de todas as formas dos organismos fitoplanctônicos, pois existe grande diversidade de tamanho, amostra e mobilidade de algumas espécies algais (Di Bernardo, 1995).

Nas concentrações de bactérias também foram verificadas mudanças rápidas em seus valores. Essas mudanças bruscas foram constatadas através das variações das medidas feitas na água do reservatório em laboratório. As variações bruscas do crescimento bacteriano são devidos às diferentes condições do meio ambiente como temperatura, $\mathrm{pH}$, necessidade de oxigênio e nutrientes (Soares \& Maia, 1999). Para a maioria das bactérias, o pH ótimo de crescimento se localiza entre 6,5 e 7,5. $\mathrm{O} \mathrm{pH}$ da água do reservatório variou em média de 7,39 (segundo período de coleta) a 6,88 (terceiro período de coleta). Quando ocorrem mudanças bruscas de valores com relação aos parâmetros biológicos, em razão de fatores relacionados com o meio ambiente, pode haver o comprometimento da eficiência de filtragem dos sistemas de irrigação localizada e, conseqüentemente, a ocorrência de problemas de obstrução dos emissores (Nakayama \& Bucks, 1991).

Foi notório o crescimento constante dos valores médios, tanto de turbidez, quanto da concentração de sólidos suspensos da água do reservatório de irrigação. Mesmo crescendo, na média cerca de nove vezes da primeira para a quarta etapa, a concentração de sólidos suspensos não atingiu magnitudes muito elevadas, a ponto de oferecer riscos médios ou altos de entupimento dos emissores, de acordo com a classificação de Nakayama \& Bucks (1986).

A turbidez é um indicador de sólidos suspensos, mas somente ela não é um parâmetro preciso para se determinar o grau de risco de entupimento de emissores para fontes de água superficial (Pitts et al., 1990). Este parâmetro físico deveria ser um parâmetro analisado conjuntamente em teste de filtragem em laboratório, para poder mensurar o potencial de risco de entupimento de emissores (Gilbert \& Ford, 1986).

\section{Influência da fertirrigação sobre a qualidade da água de irrigação}

A última fase foram feitas algumas análises a fim de se verificar a influência da injeção de fertilizantes sobre a qualidade da água de irrigação. As análises realizadas foram de turbidez e concentração de sólidos suspensos da água. Os pontos de coleta de amostras de água, foram: antes da injeção (correspondente à água do reservatório), depois da injeção (a água que chega até os filtros) e do próprio tanque reservatório com a solução fertilizante. As amostras eram tomadas simultaneamente.

As Figuras 2 e 3 contêm os resultados das análises realizadas nas quarta e última fases do experimento para avaliação da influência da fertirrigação sobre a qualidade da água utilizada na irrigação. Observa-se, na Figura 2, que as medidas efetuadas após o ponto de injeção de fertilizantes apresentaram, em 6 dos 10 ensaios, valores superiores àqueles

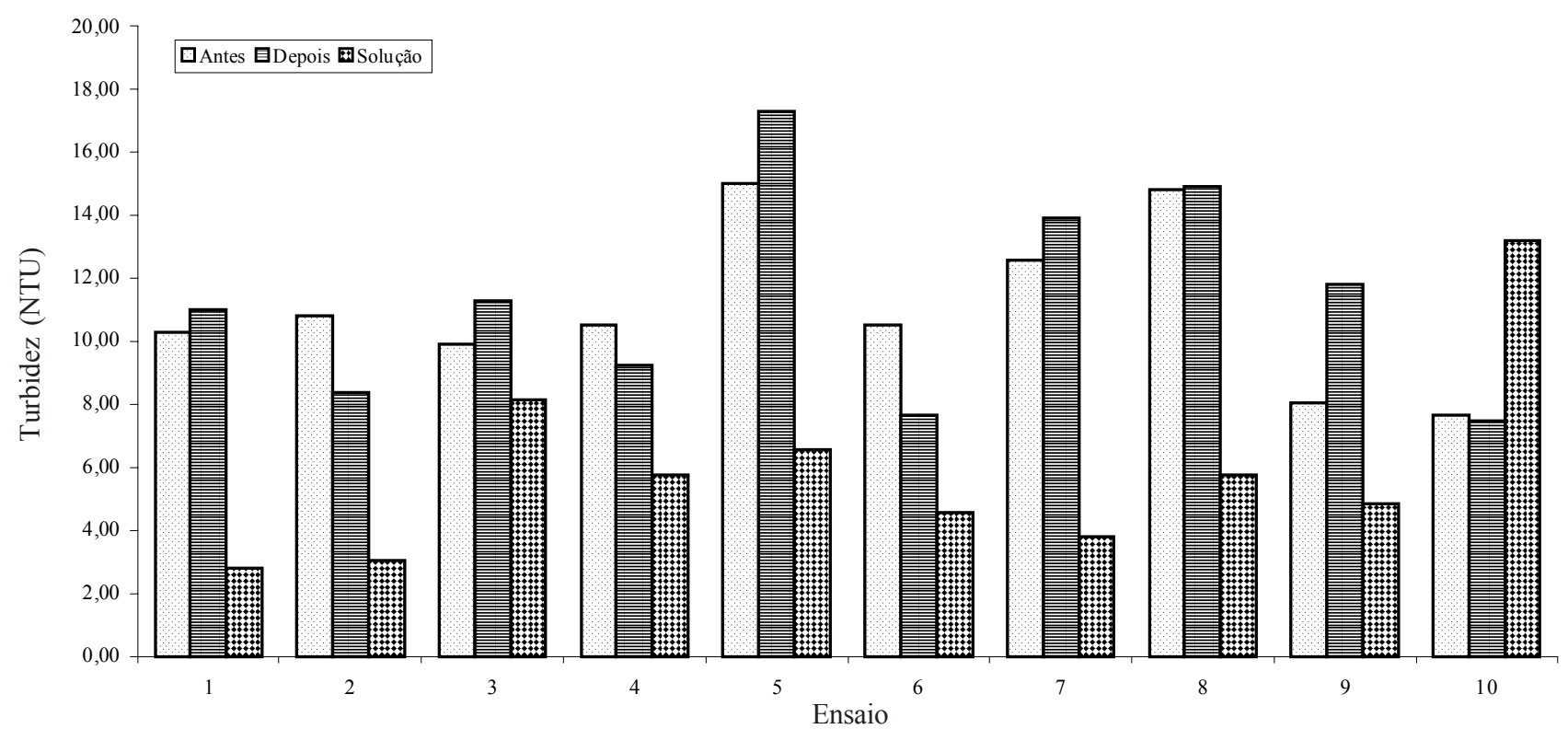

Figura 2. Variação da turbidez da água, antes e depois do ponto de injeção de fertilizantes e da própria solução fertilizante, na última etapa da pesquisa 


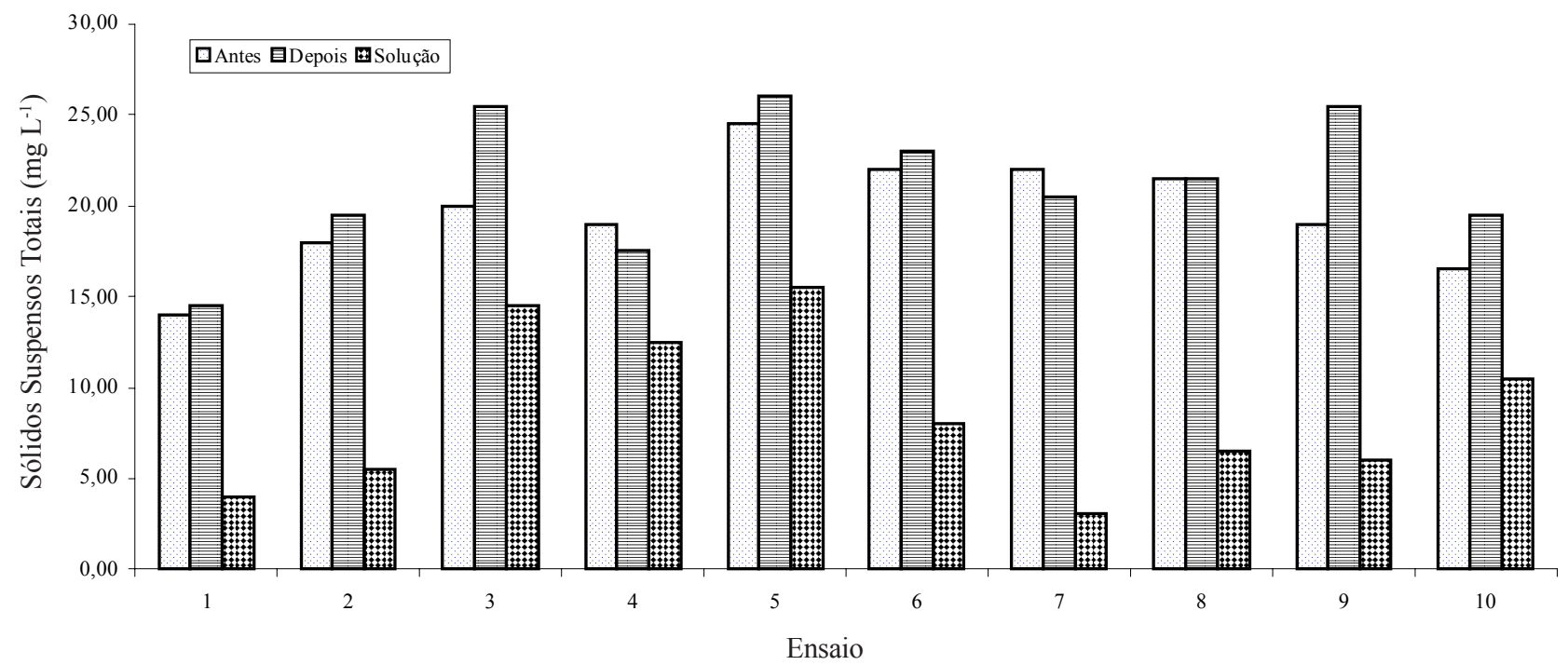

Figura 3. Variação da concentração de sólidos suspensos totais da água antes e depois do ponto de injeção de fertilizantes e da própria solução fertilizante, na quarta etapa da pesquisa.

obtidos nas amostras coletadas antes do ponto de injeção de fertilizantes; além disso, nota-se alta variabilidade nos dados referentes à própria solução fertilizante, indicando que, ao longo do tempo, ocorre variação na qualidade de água no interior do tanque reservatório da solução; já no décimo ensaio o valor da turbidez da água do reservatório supera o valor medido tanto antes como após o ponto de injeção; houve aí, sem dúvida, um rápido desenvolvimento de algas e bactérias, em função da abundância de nutrientes na solução, que resultou em elevação da turbidez da água.

Nota-se alta correlação entre a variação da turbidez da água da solução fertilizante e a sua concentração de sólidos suspensos totais. Certamente a turbidez da solução de fertilizante é muito mais afetada com o desenvolvimento de algas e bactérias no interior do tanque que a concentração de sólidos suspensos. Em nenhum momento a concentração de sólidos em suspensão na solução apresentou valor próximo aos obtidos nos outros dois pontos de coleta. Verifica-se, também, que a concentração de sólidos suspensos totais da água, medida após o ponto de injeção de fertilizantes, foi igual ou superior à concentração obtida antes deste ponto, em 8 dos 10 ensaios realizados nesta etapa.

Com os resultados, pode-se afirmar que existe influência da fertirrigação sobre a qualidade de água de irrigação, evidenciada pela elevação tanto da turbidez quanto da concentração de sólidos em suspensão da água após o ponto de introdução de fertilizantes na água de irrigação.

\section{Água efluente dos elementos filtrantes}

As amostragens foram feitas antes e após os elementos filtrantes. As primeiras representam a água advinda do reservatório e, após, a que passa pelos filtros de manta e de disco com tratamento com cloro. Desta maneira, foram determinadas as concentrações de algas, bactérias, turbidez e sólidos suspensos totais na água. As parcelas são abastecidas pela água do reservatório e sofrem a influência da fertirrigação; portanto, não foram consideradas as remoções dos filtros de manta e disco como a diferença entre a medida de determinado parâmetro de qualidade da água medido antes e após os filtros, porque a injeção de fertilizantes ocorre num ponto intermediário; assim, a comparação entre os elementos filtrantes passou a ser direta, a partir das medidas feitas após os filtros. Em princípio, não se imaginava que a baixa concentração de fertilizantes pudesse incorrer em mudanças mensuráveis de determinados parâmetros analisados.

$\mathrm{Na}$ Tabela 2, estão todos os resultados obtidos dos ensaios realizados durante o ano, das amostras de água coletadas após a passagem pelos filtros. Cada etapa foi realizada em diferentes épocas do ano, para melhor caracterizar as variações ocorridas nos efluentes, ao longo do ano. A primeira etapa foi no inverno, a segunda na primavera, a terceira no verão e a quarta no outono.

Verifica-se que na primeira etapa da pesquisa, o filtro de manta obteve melhores resultados, tanto para turbidez quanto para a concentração de sólidos suspensos, por apresentar, na média e no desvio padrão, valores menores após o filtro para os dois parâmetros físicos; já para os parâmetros biológicos ocorreu o contrário e o filtro de disco mostrou melhor desempenho (Tabela 2); nas segunda, terceira e quarta etapas, os dois filtros apresentaram resultados muitos próximos para os parâmetros físicos com relação à média e desvio padrão, $\mathrm{e}$ para os biológicos os mesmo resultados foram próximos nas segunda e terceira etapas enquanto na última o filtro de manta mostrou melhores valores com relação à bactéria e pior para algas, já que a concentração de bactéria era menor após o filtro manta e maior quando se compara a concentração de algas após o filtro de disco.

Analisando-se a Tabela 2, nota-se que as concentrações de algas e bactérias apresentaram coeficientes de variação elevados durante cada estação do ano, além de variações significativas entre as estações. A mudança dinâmica da população de algas pode representar um risco ao sistema se não houver um tratamento eficiente da água de irrigação e indica grande sensibilidade desses organismos com relação à variação da qualidade da água. As variações sazonais de algas em regiões tropicais, onde a luz e a temperatura da água não variam muito durante o ano, são devidos ao efeito das chuvas ou à seca e, 
Tabela 2. Parâmetros físicos e biológicos na água após os filtros, durante as quatro etapas da pesquisa.

\begin{tabular}{|c|c|c|c|c|c|c|c|c|c|}
\hline & \multicolumn{4}{|c|}{ Físicos } & \multicolumn{4}{|c|}{ Biológicos } \\
\hline & & \multicolumn{2}{|c|}{$\begin{array}{l}\text { Sólidos Suspensos } \\
\quad\left(\mathrm{mg} \mathrm{L}^{-1)}\right)\end{array}$} & \multicolumn{2}{|c|}{$\begin{array}{c}\text { Turbidez } \\
\text { (NTU) }\end{array}$} & \multicolumn{2}{|c|}{$\begin{array}{l}\text { Algas } \\
\left(\mathrm{n}^{0} \mathrm{~cm}^{-3}\right)\end{array}$} & \multicolumn{2}{|c|}{$\begin{array}{l}\text { Bactérias } \\
\left(\mathrm{n}^{0} \mathrm{~cm}^{-3}\right)\end{array}$} \\
\hline & & $\begin{array}{l}\text { Filtro } \\
\text { Manta }\end{array}$ & $\begin{array}{l}\text { Filtro } \\
\text { Disco }\end{array}$ & $\begin{array}{l}\text { Filtro } \\
\text { Manta }\end{array}$ & $\begin{array}{l}\text { Filtro } \\
\text { Disco }\end{array}$ & $\begin{array}{l}\text { Filtro } \\
\text { Manta }\end{array}$ & $\begin{array}{l}\text { Filtro } \\
\text { Disco }\end{array}$ & $\begin{array}{l}\text { Filtro } \\
\text { Manta }\end{array}$ & Filtro Disco \\
\hline \multirow{5}{*}{ 䔍 } & Variação & $0-5$ & $0-5$ & $1,57-9,68$ & $1,93-14,9$ & $115-420$ & $115-345$ & $1-1500$ & $2-1100$ \\
\hline & Média & 0,90 & 1,75 & 3,22 & 5,03 & 271 & 216 & 623,90 & 555,60 \\
\hline & Desv. Pad. ${ }^{1}$ & 1,10 & 1,87 & 2,33 & 4,13 & 96,32 & 84,81 & 548,11 & 484,56 \\
\hline & C.V. ${ }^{2}(\%)$ & 122,28 & 107,12 & 72,51 & 82,12 & 35,54 & 39,27 & 87,85 & 87,21 \\
\hline & R.E. ${ }^{3}$ & B & B & $\mathrm{S} / \mathrm{C}$ & $\mathrm{S} / \mathrm{C}$ & $\mathrm{S} / \mathrm{C}$ & $\mathrm{S} / \mathrm{C}$ & B & B \\
\hline \multirow{5}{*}{ 盾 } & Variação & $6,5-10,5$ & $7,5-12$ & $4,66-10,5$ & $4,14-9,5$ & $375-925$ & $405-1205$ & $1-2000$ & $1-2000$ \\
\hline & Média & 9,5 & 10 & 7,53 & 7,45 & 711,67 & 700,00 & 436,33 & 456,42 \\
\hline & Desv. Pad. ${ }^{1}$ & 1,53 & 1,75 & 1,57 & 1,46 & 178,24 & 214,95 & 783,04 & 774,99 \\
\hline & C.V. ${ }^{2}(\%)$ & 16,10 & 17,50 & 20,84 & 19,59 & 25,04 & 30,70 & 179,46 & 169,72 \\
\hline & R.E. $^{3}$ & B & B & $\mathrm{S} / \mathrm{C}$ & $\mathrm{S} / \mathrm{C}$ & $\mathrm{S} / \mathrm{C}$ & $\mathrm{S} / \mathrm{C}$ & B & B \\
\hline \multirow{5}{*}{$\begin{array}{l}\text { n } \\
\text { 芯 } \\
\text { 壱 }\end{array}$} & Variação & $12-18,5$ & $11-26$ & $10,6-13,9$ & $9,13-16,4$ & $310-1410$ & $320-1405$ & $6-600$ & $3-500$ \\
\hline & Média & 16,61 & 17,76 & 11,76 & 12,05 & 830,00 & 801,67 & 121,89 & 118,11 \\
\hline & Desv. Pad. ${ }^{1}$ & 3,33 & 4,71 & 1,89 & 2,77 & 396,64 & 416,78 & 202,13 & 171,49 \\
\hline & C.V. ${ }^{2}(\%)$ & 20,07 & 26,54 & 16,05 & 23,00 & 47,79 & 51,99 & 165,83 & 145,19 \\
\hline & R.E. $^{3}$ & B & B & $\mathrm{S} / \mathrm{C}$ & $\mathrm{S} / \mathrm{C}$ & $\mathrm{S} / \mathrm{C}$ & $\mathrm{S} / \mathrm{C}$ & B & B \\
\hline \multirow{5}{*}{ 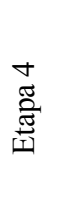 } & Variação & $14-25,5$ & $13,5-24,5$ & $4,44-13,5$ & $5,91-14,4$ & $325-1125$ & $345-750$ & $1-1900$ & $10-2600$ \\
\hline & Média & 18,75 & 19,15 & 9,17 & 9,98 & 615,00 & 530,50 & 227,60 & 305 \\
\hline & Desv. Pad. ${ }^{1}$ & 3,39 & 3,38 & 2,84 & 2,75 & 269,78 & 136,37 & 589,2 & 808,20 \\
\hline & C.V. ${ }^{2}(\%)$ & 18,10 & 17,62 & 30,93 & 27,53 & 43,87 & 25,71 & 258,8 & 264,98 \\
\hline & R.E. ${ }^{3}$ & $\mathrm{~B}$ & B & $\mathrm{S} / \mathrm{C}$ & $\mathrm{S} / \mathrm{C}$ & $\mathrm{S} / \mathrm{C}$ & $\mathrm{S} / \mathrm{C}$ & B & B \\
\hline
\end{tabular}

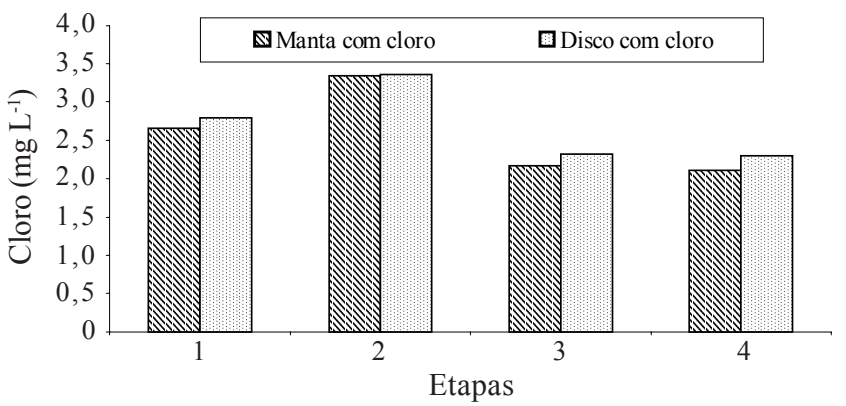

Figura 4. Média da concentração de cloro livre nos filtros de manta e disco para as quatro etapas

fundamentalmente, da ação dos ventos. A coincidência entre uma ligeira diminuição da temperatura e aumento da intensidade e da duração de ventos, pode causar a circulação da água em profundidades maiores e, conseqüentemente, uma variação brusca na concentração de algas. Para estudos quantitativos de algas, há necessidade de se levar em conta que a distribuição espacial das populações de algas não é uniforme e que variações, tanto sazonais quanto espaciais, podem ser apreciáveis. Não há um método universal para a coleta de amostra que garanta a presença de todas as formas dos organismos fitoplanctônicos, pois existe grande diversidade de tamanho, amostra e mobilidade de algumas espécies algais (Di Bernardo, 1995).

Quando ocorrem mudanças bruscas de valores com relação aos parâmetros biológicos, relativos a fatores relacionados ao meio ambiente, pode haver o comprometimento da eficiência de filtragem dos sistemas de irrigação localizada e, em conseqüência, a ocorrência de problemas de obstrução dos emissores (Nakayama \& Bucks, 1991).

\section{Efeito da cloração nos filtros}

Coletaram-se amostras de água após os filtros, que receberam a coloração para se determinar as concentrações de cloro livre e, desta maneira, comparar em qual dos elementos filtrantes ocorreu maior consumo. As concentrações foram previstas para serem de aproximadamente $2 \mathrm{mg} \mathrm{L}^{-1}$ de cloro livre após os filtros, conforme a metodologia adotada nesta pesquisa.

O gráfico da Figura 4 apresenta os resultados das médias das concentrações de cloro nas quatro fases da pesquisa. Observa-se, nas duas primeiras etapas, que as médias das concentrações de cloro livre foram maiores e ocorreu redução nas outras duas, para ambos os filtros. As variações de cloro livre foram devidas à variação da qualidade da água ao longo do ano, com relação às concentrações de algas e bactérias.

Para Soares \& Maia (1999), existe uma série de fatores que influenciam a ação bactericida do cloro, podendo-se citar: teor de matéria orgânica oxidável, concentração de microrganismos, pH da água, temperatura, tempo de contato e composição química da água (presença de sais de ferro, amônia, etc.). Notase, também, que as concentrações de cloro livre foram sempre maiores nos efluentes do filtro de disco durante todas as etapas, que o elemento filtrante de manta sintética não tecida apresenta maior permeabilidade causando, assim, maior retenção de impurezas e, conseqüentemente, também maior consumo de cloro livre. 


\section{CONCLUSÕES}

1. A qualidade da água de irrigação mostrou alto risco de entupimento nos emissores, com relação ao sulfeto de hidrogênio, nas duas últimas etapas, enquanto no $\mathrm{pH}$ e no ferro o risco de entupimento foi considerado médio durante as quatro etapas de experimentação; para os demais itens analisados, o risco de entupimento foi considerado baixo.

2. Dos três parâmetros analisados na água de irrigação, o biológico foi o que apresentou maior coeficiente de variação, enquanto a concentração de bactéria indicou a maior variação.

3. A concentração de sólidos suspensos e a turbidez dos efluentes dos filtros de manta e disco foram muito próximos, em todas as etapas.

4. As menores concentrações de alga foram encontradas nos efluentes da parcela com filtro de disco e as menores concentrações de bactérias nos efluentes da parcela com filtro de manta.

5. A solução fertilizante injetada alterou a qualidade de água de irrigação, marcada pela elevação tanto da turbidez quanto da concentração de sólidos em suspensão, após o ponto de injeção de fertilizantes na água de irrigação.

6. A concentração média de cloro livre foi maior no efluente do filtro de disco durante todas as etapas da pesquisa.

\section{AGRADECIMENTOS}

Os autores agradecem à FAPESP o auxílio financeiro para a realização deste projeto (Processo: 00/01292-5) e bolsas de estudo concedidas (Processos: 01/02058-9 e 01/01719-1).

\section{LITERATURA CITADA}

Adin, A.; Alon, G. Mechanisms and process parameters of filter screens. Journal of Irrigation and Drainage Engineering, Jerusalem, v.112, n.4, 293-304, 1986.

APHA, American Public Health Association. Heterotrophic plate count. In: Standard methods for examination of water and wastewater. Washington D.C.: 1992 p.9.32-9.34.

APHA, AWWA, WPCF. "Standard methods for the examination of water and wastewater". $16^{\circ}$ ed. Washington, D.C. 1985 , $1268 \mathrm{p}$.

Branco, S. M.. Hidrologia aplicada à engenharia sanitária. 2 ed. São Paulo: CETESB, 1986. 620p
Di Bernardo, L. Algas e suas influências na qualidade das águas e nas tecnologias de tratamento. Rio de Janeiro: ABES, 1995. $140 \mathrm{p}$.

English, S.D. Filtration and water treatment for micro-irrigation. In. Internacional Drip/Trickle Irrigation Congress, 3, Fresno, Proceedings. St Joseph: ASAE, 1985, p. 50-57.

Ford, H.A.; Tucker, D.P.H. Clogging of drip systems from metabolic products of iron and sulfur bacteria. International Drip Irrigation. Congress, Proceedings... San Diego: 1986 p.212-214

Gilbert, R.G.; Ford, H.W. Operational principles/emiter clogging. In: Nakayama, F.S.; Bucks, D.A. Trickle irrigation for crop production. Amsterdam: Elsevier, 1986cap. 3. p.142-163.

Gilbert, R.G.; Nakayama, F.S.; Bucks, D.A.; French, O.F.; Adamson, K.C. Trickle irrigation: emitter clogging and other flow problems. Agricultural Water Management, Amsterdam, v.3, n.3, p.159-178, 1981.

Nakayama, F.S; Bucks, D.A. Trickle irrigation for crop production: Design, operation and management. Amsterdam, Elsevier, 1986, p.164.

Nakayama, F.S.; Bucks, D.A. Emitter clogging effects on trickle irrigation uniformity. Transaction of the ASAE, St Joseph, v.24, p.77-80, 1991.

Nakayama, F.S.; Bucks, D.A.; French, O.F. Reclaiming partially clogged trickle emitters. Transactions of the ASAE, St. Joseph. v.20, n.2, p.278-280, 1977.

Paterniani, J.E.S.; Silva, L.B. Comparação entre diferentes meios filtrantes de filtros para irrigação localizada. Congresso Argentino 4 e Congresso Internacional de Ingenieria Rural 2, 1996, Neuquen, Argentina.Anais... p.397-401. 1996.

Pitts, D.J.; Haman, D.Z.; Smajstla, A.G. Causes and prevention of emitter plugging in microirrigation systems. University of Florida, Florida Cooperative Extension Service, 1990, 12p. Bulletin 258

Pizarro, F. Riegos localizados de alta frequencia. 3 ed. Madrid: Ed. Mundi Prensa, 1996. 471p.

Scatolini, M.E. Utilização de mantas não-tecidas como elemento filtrante em sistemas de irrigação localizada, Campinas: FEAGRI/UNICAMP, 2001. Tese Doutorado

Soares, J.B.; Maia, A.C.F. Água: microbiologia e tratamento. Fortaleza:UFC, 1999. 206p.

Testezlaf, R.; Matsura, E.E.; Roston, D.M.; Paula Jr., D.R.; Paterniani, J.E.; Ribeiro, T.A.P. Potencialidade do uso de irrigação por gotejamento em propriedades agrícolas produtoras de hortaliças da região de Campinas, SP. Congresso Brasileiro de Irrigação e Drenagem, 10, Salvador; Anais... Salvador: ABID, 1994. 